Helen Dolk, DrPH

Hao Wang, PhD

Maria Loane, $\mathrm{PhD}$

Joan Morris, $\mathrm{PhD}$

Ester Garne, MD

Marie-Claude Addor, MD

Larraitz Arriola, MD

Marian Bakker, PhD

Ingeborg Barisic, $\mathrm{MD}$

Berenice Doray, PhD, MD

Miriam Gatt, MSc

Karin Kallen

Babak Khoshnood, MD,

$\mathrm{PhD}$

Kari Klungsoyr, PhD

(DrMed)

Anna-Maria Lahesmaa-

Korpinen, $\mathrm{PhD}$

Anna Latos-Bielenska

Jan P. Mejnartowicz,

$\mathrm{MD}, \mathrm{PhD}$

Vera Nelen, MD

Amanda Neville, BSc Hons

Mary O'Mahony,

MFPHMI

Anna Pierini, MSc

Anke Rißmann, MD

David Tucker, MPH

Diana Wellesley, FRCP

Awi Wiesel, MSc

Lolkje T.W. de Jong-van den Berg, PhD

Correspondence to

Dr. Dolk:

h.dolk@ulster.ac.uk

Supplemental data at Neurology.org

\title{
Lamotrigine use in pregnancy and risk of orofacial cleft and other congenital anomalies OPEN
}

\section{ABSTRACT}

Objective: To test previous signals of a risk of orofacial cleft $(\mathrm{OC})$ and clubfoot with exposure to the antiepileptic lamotrigine, and to investigate risk of other congenital anomalies (CA).

Methods: This was a population-based case-malformed control study based on 21 EUROCAT CA registries covering 10.1 million births (1995-2011), including births to 2005 in which the clubfoot signal was generated and a subsequent independent study population of 6.3 million births. A total of 226,806 babies with CA included livebirths, stillbirths, and terminations of pregnancy following prenatal diagnosis. First-trimester lamotrigine monotherapy exposure in OC cases and clubfoot cases was compared to other nonchromosomal CA (controls). Odds ratios (OR) were adjusted for registry. An exploratory analysis compared the proportion of each standard EUROCAT CA subgroup among all babies with nonchromosomal CA exposed to lamotrigine monotherapy with non-AED exposed pregnancies.

Results: There were 147 lamotrigine monotherapy-exposed babies with nonchromosomal CA. For all OC, OR adj was 1.31 (95\% confidence interval [Cl] 0.73-2.33), isolated OC $1.45(95 \% \mathrm{Cl}$ $0.80-2.63)$, isolated cleft palate $1.69(95 \% \mathrm{Cl} 0.69-4.15)$. Overall $\mathrm{OR}_{\text {adj }}$ for clubfoot was 1.83 (95\% Cl 1.01-3.31) and $1.43(95 \% \mathrm{Cl} 0.66-3.08)$ in the independent study population. No other specific CA were significantly associated with lamotrigine monotherapy.

Conclusions: The risk of $O C$ was not significantly raised and we estimate the excess risk of $O C$ to be less than 1 in every 550 exposed babies. We have not found strong independent evidence of a risk of clubfoot subsequent to our original signal. Our study cannot assess the general malformation risk among lamotrigine-exposed pregnancies. Neurology ${ }^{\circledR}$ 2016;86:1716-1725

\section{GLOSSARY}

AED = antiepileptic drug; $\mathbf{C A}$ = congenital anomaly; $\mathbf{C I}=$ confidence interval; EAC = external advisory committee; ICD-9/ $\mathbf{1 0}=$ International Classification of Diseases-9/10; OC = orofacial cleft; OR = odds ratio; TOPFA = termination of pregnancy for fetal anomaly; VPA = valproic acid.

Lamotrigine is commonly used for both epilepsy and bipolar disorder. ${ }^{1,2}$ Evidence of a good teratogenic safety profile relative to other antiepileptic drugs (AED), with an overall congenital anomaly (CA) risk close to background expectation in cohort studies, ${ }^{3-6}$ has encouraged use for women of childbearing age and pregnant women. ${ }^{1}$ However, there are concerns about pharmacokinetics and seizure risk in pregnancy ${ }^{5,7}$ and lamotrigine is not effective for some people with epilepsy. ${ }^{8}$ A warning about the specific risk of orofacial clefts (OC) is given in patient information (Medicines and Healthcare Products Regulatory Agency 2015), due to a signal

From Ulster University (H.D., M.L.), Northern Ireland, UK; University of Groningen (H.W., L.T.W.d.J.-v.d.B.), the Netherlands; Barts and the London School of Medicine and Dentistry (J.M.), UK; Hospital Lillebaelt (E.G.), Kolding, Denmark; Registre Vaudois des Malformations

(M.-C.A.), Lausanne, Switzerland; Public Health Division of Gipuzkoa (L.A.), Instituto BIO-Donostia, Basque Government, CIBER Epidemiología y Salud Pública-CIBERESP, Madrid, Spain; University Medical Centre Groningen (M.B.), the Netherlands; Children's University Hospital Zagreb (I.B.), Croatia; Registre des Malformations Congenitales D’Alsace (B.D.), University of Strasbourg, France; Department of Health Information and Research (M.G.), Malta; Swedish National Board of Health and Welfare (K. Kallen), Stockholm, Sweden; Institut National de la Sante et de la Recherche Medicale (B.K.), INSERM, Villejuif, France; Medical Birth Registry of Norway (K. Klungsoyr), Oslo; National Institute for Health \& Welfare (A.-M.L.-K.), Helsinki, Finland; Poznan University of Medical Sciences (A.L.-B., J.P.M.), Poland; Provinciaal Instituut voor Hygiene (V.N.), Antwerp, Belgium; Center for Clinical and Epidemiological Research Ferrara (A.N.), Italy; Health Service Executive (M.O.), Kildare, Ireland; Institute of Clinical Physiology-National Research Council (IFC-CNR) (A.P.), Pisa, Italy; Otto-von-Guericke University Magdeburg (A.R.), Germany; Public Health Wales NHS Trust (D.T.), Congenital Anomaly Register and Information Service for Wales; Wessex Clinical Genetics Service (D.W.), Princess Anne Hospital, UK; and University Medical Center of Mainz Birth Registry Mainz Model (A.W.), Germany. Go to Neurology.org for full disclosures. Funding information and disclosures deemed relevant by the authors, if any, are provided at the end of the article. The Article Processing Charge was paid by the authors.

This is an open access article distributed under the terms of the Creative Commons Attribution-NonCommercial-NoDerivatives License 4.0 (CC BYNC-ND), which permits downloading and sharing the work provided it is properly cited. The work cannot be changed in any way or used commercially. 
from the North American AED registry of a 6-fold risk of OC, specifically cleft palate. ${ }^{9,10}$ A number of studies have been published since, ${ }^{6,11-13}$ none of which has produced further evidence to support an excess risk of this magnitude.

EUROCAT is network of populationbased CA registries. ${ }^{14}$ In 2008, we tested the signal of an increased risk of OC with lamotrigine monotherapy by analyzing data from 19 registries for the period $1995-2005 .{ }^{13}$ In an exploratory analysis, we found evidence of an excess risk of clubfoot, which could have been a chance finding and constituted a signal requiring confirmation in independent data. ${ }^{13}$ Our objective in this new study was to enlarge the study population in order to estimate more precisely the relative risk of $\mathrm{OC}$, to follow-up the clubfoot signal, and to explore evidence of risk of other CA subgroups.

\section{METHOD Study design.}

1. Case-malformed control design to test OC and clubfoot signals.

2. Exploratory analysis comparing proportion of each CA subgroup between lamotrigine-exposed and non-AED-exposed.

Study population and registry data. The EUROCAT central database contains anonymized, individual CA registrations, including livebirths, fetal deaths from 20 weeks' gestation, and terminations of pregnancy for fetal anomaly (TOPFA). One syndrome and up to 8 anomalies are coded by ICD-9/10 codes. ${ }^{15}$ Babies with only minor anomalies according to the EUROCAT list ${ }^{15}$ are excluded. Other variables include maternal age, maternal disease before and during pregnancy (ICD coded + text), and medications taken in the first trimester of pregnancy (Anatomical Therapeutic Chemical coded $\left.^{16}\right) .{ }^{15}$ Information about maternal medication exposure is mainly obtained from medical records of pregnancy, and some registries also use maternal interviews after birth or prescription databases (table 1$){ }^{17}$

\begin{tabular}{|c|c|c|c|c|c|}
\hline \multicolumn{6}{|c|}{$\begin{array}{l}\text { Overview of participating registries: Region/country, source of medication exposure information, study years, total birth population } \\
\text { covered, total major congenital malformation (MCM) registrations }\end{array}$} \\
\hline Registry & EAM $^{a}$ & Birth years (independent study population) ${ }^{b}$ & Total births & MCM no. & MCM \% \\
\hline Belgium, Antwerp & M & $1997-2011(2006-2011)$ & 286,751 & 7,107 & 2.48 \\
\hline Belgium, Hainaut & $\mathrm{M}, \mathrm{P}$ & 1997-2005 (none) & 110,557 & 2,971 & 2.69 \\
\hline Croatia, Zagreb & M & $1995-2010(2005-2010)$ & 105,353 & 1,813 & 1.72 \\
\hline Denmark, Odense & M & $1995-2011(2005-2011)$ & 92,211 & 2,542 & 2.76 \\
\hline Finland & $\mathrm{P}$ & 1996-2008 (all) & 753,000 & 22,839 & 3.03 \\
\hline France, Paris & M & $1997-2011(2006-2011)$ & 508,721 & 17,430 & 3.43 \\
\hline France, Strasbourg & M & 1997-2004 (2003-2004) & 102,495 & 3,351 & 3.27 \\
\hline Germany, Mainz & $\mathrm{M}, \mathrm{O}$ & 1996-2011 (2005-2011) & 52,190 & 2,485 & 4.76 \\
\hline Germany, Saxony-Anhalt & $\mathrm{M}, \mathrm{I}$ & $1996-2011$ (2006-2011) & 250,210 & 8,045 & 3.22 \\
\hline Ireland, Cork \& Kerry & M & 1996-2010 (2004-2010) & 131,119 & 3,400 & 2.59 \\
\hline Italy, Emilia Romagna & $\mathrm{M}, \mathrm{I}$ & 2000-2011 (2005-2011) & 426,954 & 8,455 & 1.98 \\
\hline Italy, Tuscany & $M, I$ & 2002-2011 (2006-2011) & 296,483 & 6,254 & 2.11 \\
\hline Malta & M & $1996-2010$ (2005-2010) & 63,051 & 2,020 & 3.20 \\
\hline Netherlands, North & $M, I, P$ & $1995-2011(2006-2011)$ & 323,728 & 8,620 & 2.66 \\
\hline Norway & M & $1999-2011(2006-2011)$ & 713,503 & 23,423 & $3.28^{\mathrm{c}}$ \\
\hline Poland & $M, I$ & $1999-2010(2005-2010)$ & $3,228,380$ & 47,851 & 1.48 \\
\hline Poland, Wielkopolska & $\mathrm{M}, \mathrm{I}$ & $1999-2010(2005-2010)$ & 440,096 & 11,269 & 2.56 \\
\hline Spain, Basque Country & $\mathrm{M}, \mathrm{P}$ & $1995-2010(2006-2010)$ & 297,531 & 5,999 & 2.02 \\
\hline Sweden & M & 1999-2011 (all) & $1,300,269$ & 18,718 & $1.44^{\mathrm{c}}$ \\
\hline Switzerland, Vaud & $\mathrm{M}, \mathrm{O}$ & $1997-2011(2006-2011)$ & 112,156 & 4,378 & 3.90 \\
\hline UK, Wales & M & 1998-2011 (2006-2011) & 466,301 & 17,836 & 3.82 \\
\hline Total & & & $10,061,059$ & 226,806 & 2.25 \\
\hline
\end{tabular}

Abbreviation: $\mathrm{EAM}=$ exposure ascertainment method.

a Prospectively recorded maternity records (M), maternal interview after birth (I), prescription records (P), other (e.g., pediatrics or clinical genetics records) (O). Basque Country added P from 2010 only.

${ }^{\mathrm{b}}$ Independent study population refers to births in those years not included in previous study. ${ }^{13}$ Note that previous study data (e.g., late CA diagnoses) have been updated.

${ }^{\mathrm{c}}$ All MCM includes terminations of pregnancy for fetal anomaly (TOPFA) except in Norway and Sweden. Total MCM prevalence in Norway including TOPFA registrations: 3.63\%; total MCM prevalence in Sweden 2007-2011 including TOPFA registrations: 2.20\%. 
Twenty-one population-based registries participated-the 19 registries of the previous study, ${ }^{13}$ and Finland and Sweden, which as associate EUROCAT members transmitted data for this study. The study population comprised 10.1 million births from 1995 to 2011 (table 1), of which 6.3 million were an independent study population (table 1). One woman may have more than one baby in the study population.

TOPFA were excluded in Norway and Sweden due to lacking medication exposure information. TOPFA in Emilia Romagna and Saxony-Anhalt were retained despite known exposure underascertainment.

Classification of congenital anomalies. There were 226,806 CA registrations in the study population, divided into nonchromosomal $(\mathrm{n}=199,515,88 \%)$ and chromosomal CA $(\mathrm{n}=$ 27,291, 12\%). Nonchromosomal CA were classified into EUROCAT standard CA subgroups. ${ }^{15}$ One baby can be counted in more than one subgroup, but each baby is counted only once when subgroups are combined. OC cases were divided into isolated and multiply malformed (at least 2 major anomalies not part of a syndrome, sequence, or complex) according to Coding \& Classification panel case review. ${ }^{18}$ Diagnoses of all lamotrigineexposed registrations were also reviewed by the panel.

Exposure definition. Registrations with maternal epilepsy or AED exposure were verified with registries. Exposures were classified as monotherapy or polytherapy (use of 2 or more AED types in the first trimester, concurrently or sequentially) and by type of AED (lamotrigine, any AED, any AED excluding valproic acid [VPA]). The category "any AED excluding VPA" was constructed due to established high teratogenicity of VPA. To avoid misclassification, we excluded mothers with epilepsy without recorded AED exposure (574 registrations, figure e- 1 on the Neurology ${ }^{\circledR}$ Web site at Neurology.org).

Forty-three registrations of the 259 with lamotrigine exposure (22 mono, 21 poly, including 3 chromosomal registrations) were confirmed as exposed during pregnancy but could not be confirmed as first trimester exposures and were excluded in sensitivity analyses.

Case and control definition and classification. Orofacial clefts. Cases were babies with nonsyndromic OC. Cases were excluded where $\mathrm{OC}$ was part of a chromosomal, monogenic, or teratogenic syndrome or secondary to another primary anomaly (figure $\mathrm{e}-1$ ). A subanalysis for cleft palate was performed since this was more strongly associated with lamotrigine in the original signal. ${ }^{10}$

Controls were babies with nonchromosomal major CA excluding OC.

Clubfoot. Cases were babies with nonchromosomal clubfoot excluding spina bifida sequence ( $2 \%$ of all clubfoot) (figure e- 1 ).

Controls were babies with nonchromosomal nonclubfoot major CA

Lamotrigine monotherapy-exposed clubfoot cases were further classified as unilateral/bilateral, and the exclusion of positional talipes, ${ }^{15}$ a much more common minor anomaly, was verified. For comparison, diagnostic details and treatment type were provided for a random sample of 308 out of 1,429 clubfoot registrations in 16 registries (1995-2009): for each registry (excluding Finland, Sweden, Hainaut, Poland, and Strasbourg), a random 20 clubfoot registrations, or all clubfoot registrations if fewer than 20. Of the 308 sampled registrations, a questionnaire was filled in for 301 . Thirteen cases (4.3\%) were found not to have the major anomaly clubfoot (e.g., cases of positional talipes), leaving 288 for analysis.

Statistical analysis. Crude odds ratios (ORs) were calculated first. WinBUGS was used to fit multinomial responses with a logistic link, including registries with no exposure to lamotrigine in either cases or controls, adjusting for registry. Noninformative priors were used and therefore the credible intervals are equivalent to confidence intervals (CIs). We also controlled for maternal age, treated as a categorical variable $(<20,20-24,25-29,30-34$, and $35+$ years of age). Due to the small numbers of exposures to lamotrigine, it was not possible to adjust simultaneously for both registry and maternal age. ORs adjusted for registry were a priori the outcome measure of choice due to the potential for confounding arising from differences in both CA prevalence and exposure prevalence among registries, and the lack of strong maternal age effects for most nonchromosomal anomalies. ${ }^{19}$ Modeling with Poisson regression produces almost identical results (not shown).

For the clubfoot analysis, ORs were calculated for the entire study population (table 1) and for the independent study population (table 1).

As it is not possible to estimate overall CA risk from a casemalformed control study as this would require information about nonmalformed babies, we also compared exposure to lamotrigine, and any AED, among all nonchromosomal CA combined to exposure among all chromosomal cases, assuming that exposure among chromosomal CA would represent population exposure. We calculated crude OR and OR adjusted for maternal age due to the strong relationship of maternal age to chromosomal anomalies.

In an exploratory proportional analysis, the number of babies with each nonchromosomal CA subgroup was calculated as a proportion of all babies with nonchromosomal CA, and was compared between the lamotrigine-exposed registrations and the non-AED-exposed registrations using Fisher exact test.

In a sensitivity analysis for OC, 6 OC cases (5 isolated, 1 multiply malformed) and 34 controls were excluded as lamotrigine monotherapy/polytherapy exposure was of uncertain timing during pregnancy. In a sensitivity analysis for clubfoot, 4 clubfoot cases (3 lamotrigine monotherapy, 1 lamotrigine polytherapy) including 1 case in the independent study population, and 36 controls, were excluded for the same reason.

Sensitivity analyses were also performed for the lamotrigine monotherapy analysis whereby clubfoot was excluded from the control group where cases were OC, and vice versa.

Five-year analysis strategy and external advisory committee (EAC). The study was performed over 5 years, with an interim analysis each year reviewed by an EAC consisting of a pediatrician specialized in teratology, a neurologist specialized in treatment of epilepsy in pregnancy, and a statistician. The EAC identified no concern that should lead to early publication of results. The report and comments received by the EAC and response to those comments from the research team were forwarded to GSK, who forwarded the report to the Medicines and Healthcare Products Regulatory Agency.

Standard protocol approvals, registrations, and patient consents. This study was approved by the Ulster University Ethics Committee. All contributing registries have their own ethics approval arrangements according to national laws.

RESULTS AED exposure in the CA population. AED exposure was recorded in 6.0 per 1,000 registrations (table 2). AED monotherapy accounted for $80 \%$ of AED exposure (table 2); 43\% of CA registrations with AED exposure had been exposed to VPA (table 2). Of the AED exposed, 79\% ( $\mathrm{n}=1,073)$ had maternal epilepsy recorded; others had AED for other indications, or had missing data regarding indication. 
Table 2 AED exposure among registrations (per 1,000 registrations)

\begin{tabular}{|c|c|c|c|c|}
\hline Type of AED exposure & Exposed & $\begin{array}{l}\text { Proportion per } \\
1,000 \text { registrations } \\
(1995-2011)\end{array}$ & $\begin{array}{l}\text { Proportion per } \\
1,000 \text { registrations } \\
(1995-2005)\end{array}$ & $\begin{array}{l}\text { Proportion per } \\
1,000 \text { registrations } \\
(2006-2011)\end{array}$ \\
\hline \multicolumn{5}{|l|}{$\begin{array}{l}\text { All nonchromosomal } \\
\text { registrations }\end{array}$} \\
\hline Any AED & 1,286 & 6.4 & 6.7 & 6.1 \\
\hline Any AED excluding VPA & 731 & 3.7 & 3.4 & 4.0 \\
\hline Any AED monotherapy & 1,027 & 5.1 & 5.3 & 4.9 \\
\hline $\begin{array}{l}\text { Any AED monotherapy } \\
\text { excluding VPA }\end{array}$ & 638 & 3.2 & 3.0 & 3.5 \\
\hline Any AED polytherapy & 259 & 1.3 & 1.3 & 1.2 \\
\hline $\begin{array}{l}\text { Any AED polytherapy } \\
\text { excluding VPA }\end{array}$ & 93 & 0.5 & 0.5 & 0.5 \\
\hline Lamotrigine monotherapy & 147 & 0.7 & 0.5 & 1.2 \\
\hline Lamotrigine polytherapy & $98^{\mathrm{a}}$ & 0.5 & 0.5 & 0.5 \\
\hline \multicolumn{5}{|l|}{ All registrations } \\
\hline Any AED & 1,364 & 6.0 & 6.2 & 5.7 \\
\hline Lamotrigine monotherapy & 157 & 0.7 & 0.4 & 1.1 \\
\hline Lamotrigine polytherapy & $102^{b}$ & 0.4 & 0.4 & 0.5 \\
\hline
\end{tabular}

Abbreviations: AED = antiepileptic drug; VPA = valproic acid.

${ }^{a}$ Including 55 with VPA.

${ }^{\mathrm{b}}$ Including 57 with VPA.

Twelve percent of all AED-exposed CA registrations were exposed to lamotrigine monotherapy (table 2) and 7\% to lamotrigine as part of polytherapy (table 2). Among lamotrigine monotherapy exposures, $77.1 \%$ were recorded with maternal epilepsy. The proportion of lamotrigine monotherapy exposures rose over time (table 2).

AED-exposed registrations were similar in maternal age to unexposed registrations (29.2 vs 29.6 years), and lamotrigine-exposed registrations slightly younger (28.4 years).

Registrations included $89.4 \%$ livebirths, $1.3 \%$ stillbirths or late fetal deaths, and $9.3 \%$ TOPFA. The rate of AED exposure was 6.13 per 1,000 registrations among livebirths, 5.83 per 1,000 among fetal deaths, and 4.93 per 1,000 among TOPFA.

OC. OC were significantly associated with AED exposure (All OC OR adj $_{\text {1.3 }} .34,95 \%$ CI 1.11-1.62; all cleft palate $\left.\mathrm{OR}_{\mathrm{adj}} 1.97,1.54-2.52\right)$ with lower $\mathrm{OR}$ for isolated OC/cleft palate (table 3). ORs remained elevated after excluding VPA (table 3).

For lamotrigine monotherapy, there were nonsignificant associations for all $\mathrm{OC}\left(\mathrm{OR}_{\mathrm{adj}} 1.31,95 \% \mathrm{CI}\right.$ $0.73-2.33)$ and for all cleft palate $\left(\mathrm{OR}_{\mathrm{adj}} 1.60,95 \%\right.$ CI 0.70-3.65) (table 3). The ORs for isolated OC/ cleft palate were slightly higher but nonsignificant (table 3). The ORs for all OC/cleft palate with lamotrigine monotherapy were nonsignificantly higher than those for any AED monotherapy excluding VPA (table 3).
In the sensitivity analysis excluding uncertain timing of lamotrigine exposure, adjusted ORs were diluted (all OC: $1.22,95 \%$ CI 0.63-2.34; isolated OC: $1.46,95 \%$ CI $0.76-2.80$; all cleft palate: 0.97 , 95\% CI 0.31-3.09; isolated cleft palate: $1.23,95 \%$ CI 0.39-3.89).

A sensitivity analysis excluded clubfoot from the controls: isolated OC OR 1.48 (0.74-2.69), all OC $1.33(0.69-2.36)$, isolated cleft palate $1.70(0.54-$ 4.07), and all cleft palate $1.60(0.58-3.60)$.

Diagnostic review of lamotrigine monotherapyexposed babies in the control group found 3 pairs of sibs where it is possible that the CA was genetically linked to the epilepsy of the mother: one pair with tuberous sclerosis, one with cleidocranial dysostosis (rarely linked with epilepsy), and one with lissencephaly. Exclusion of these cases from the controls in a sensitivity analysis hardly changed the OR for OC. There were no other sibpairs.

Clubfoot. There was no excess of clubfoot with any AED exposure $\left(\mathrm{OR}_{\text {adj }} 0.96,95 \%\right.$ CI $\left.0.74-1.26\right)$ (table 4). With lamotrigine monotherapy exposure, there was a significant excess of clubfoot in the entire study population $\left(\mathrm{OR}_{\mathrm{adj}} 1.83,95 \%\right.$ CI 1.01-3.31), reduced and nonsignificant in the independent study population $\left(\mathrm{OR}_{\mathrm{adj}} 1.43,95 \% \mathrm{CI} 0.66-3.08\right)$ (table 4). Excluding lamotrigine of uncertain timing did not substantially change the estimates but the lower CI limit was below 1 (overall $\mathrm{OR}_{\text {adj }} 1.60,95 \%$ CI $0.81-$ 3.15 , independent study population $\mathrm{OR}_{\mathrm{adj}} 1.40$, 
Table 3 Orofacial cleft (OC) numbers and odds ratios (ORs) (95\% confidence interval [CI]) for antiepileptic drug (AED) and lamotrigine exposure compared to no AED exposure among babies with nonchromosomal anomalies

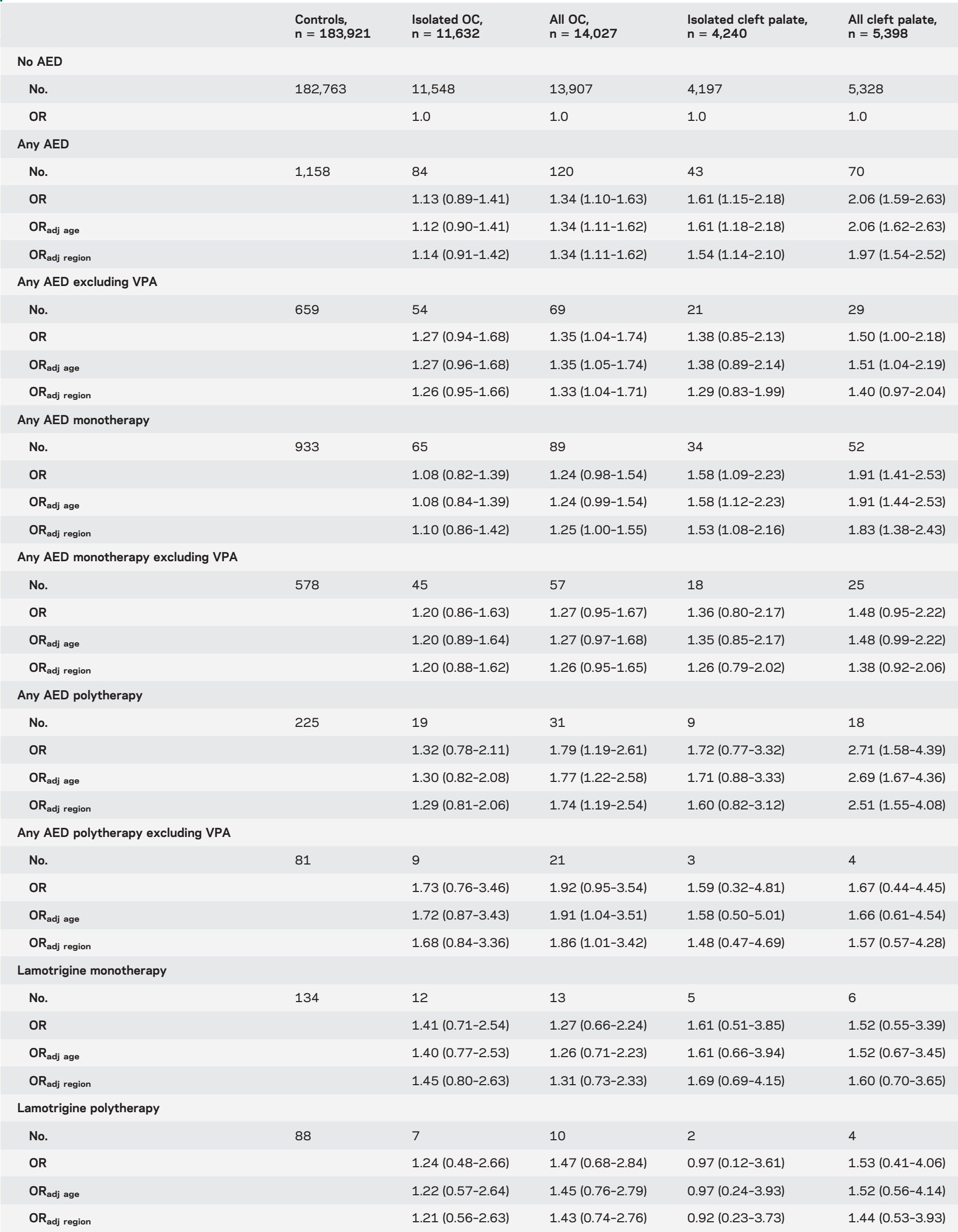

Abbreviations: $\mathrm{OR}_{\mathrm{adj}}$ age $=\mathrm{OR}$ adjusted for maternal age; $\mathrm{OR}_{\mathrm{adj}}$ region $=\mathrm{OR}$ adjusted for registry; $\mathrm{VPA}=$ valproic acid. 


\begin{tabular}{|c|c|c|c|}
\hline \multirow[t]{2}{*}{ Table 4} & \multicolumn{3}{|c|}{$\begin{array}{l}\text { Clubfoot numbers and odds ratios (OR, } 95 \% \text { confidence interval [CI]) } \\
\text { with any antiepileptic drug (AED) and lamotrigine (monotherapy and } \\
\text { polytherapy) exposure, in the entire study population (1995-2011) and } \\
\text { the independent study population }{ }^{a}\end{array}$} \\
\hline & & $\begin{array}{l}\text { Entire study } \\
1995-2011\end{array}$ & $\begin{array}{l}\text { Independent } \\
\text { study population a }\end{array}$ \\
\hline \multicolumn{2}{|l|}{ All clubfoot } & 9,134 & 5,063 \\
\hline \multicolumn{2}{|l|}{ Any AED } & 56 & 28 \\
\hline \multicolumn{2}{|l|}{ OR } & $0.96(0.72-1.25)$ & $0.84(0.55-1.23)$ \\
\hline \multicolumn{2}{|l|}{$\mathrm{OR}_{\text {adj age }}$} & $0.96(0.73-1.25)$ & $0.84(0.57-1.23)$ \\
\hline \multicolumn{2}{|c|}{$\mathrm{OR}_{\text {adj region }}$} & $0.96(0.74-1.26)$ & $0.84(0.58-1.23)$ \\
\hline \multicolumn{2}{|c|}{ Lamotrigine monotherapy } & 12 & 7 \\
\hline \multicolumn{2}{|l|}{ OR } & $1.88(0.94-3.39)$ & $1.48(0.58-3.16)$ \\
\hline \multicolumn{2}{|l|}{$\mathrm{OR}_{\text {adj age }}$} & $1.87(1.04-3.38)$ & $1.48(0.69-3.18)$ \\
\hline \multicolumn{2}{|c|}{$\mathrm{OR}_{\text {adj region }}$} & $1.83(1.01-3.31)$ & $1.43(0.66-3.08)$ \\
\hline \multicolumn{2}{|c|}{ Lamotrigine polytherapy } & 3 & 1 \\
\hline \multicolumn{2}{|l|}{ OR } & $0.67(0.14-2.02)$ & $0.35(0.01-2.04)$ \\
\hline \multicolumn{2}{|l|}{$\mathrm{OR}_{\text {adj age }}$} & $0.66(0.21-2.10)$ & $0.35(0.05-2.54)$ \\
\hline \multicolumn{2}{|c|}{$\mathrm{OR}_{\text {adj region }}$} & $0.68(0.21-2.16)$ & $0.36(0.05-2.59)$ \\
\hline
\end{tabular}

Abbreviations: $\mathrm{OR}_{\text {adj age }}=\mathrm{OR}$ adjusted for maternal age; $\mathrm{OR}_{\text {adj region }}=\mathrm{OR}$ adjusted for registry.

a The independent study population consists of registries and years not previously analyzed when generating the clubfoot signal in Dolk et al. ${ }^{13}$ It consists mainly of data since 2006, and all years for Finland and Sweden (table 1).

95\% CI 0.61-3.22). Excluding OC from the controls, OR estimates were nonsignificant: entire study population OR 1.88 (0.94-3.38), independent study population OR $1.52(0.59-3.28)$.

Of the 12 lamotrigine monoexposed clubfoot cases, 7 were bilateral and 11 were isolated, and all cases were confirmed as clubfoot (i.e., not positional talipes). This was similar to the profile in the random comparison sample of unexposed clubfoot $(55.2 \%$ bilateral, $70.8 \%$ isolated, and $62.5 \%$ of liveborn cases treated with splints/casts/surgery).

All nonchromosomal CA combined compared with all chromosomal CA. There were 147 lamotrigine monotherapy-exposed nonchromosomal CA and 10 lamotrigine monotherapy-exposed chromosomal controls, giving an OR of 1.77 (95\% CI 0.93 3.37), adjusted for maternal age. The OR adjusted for maternal age for any AED was 2.25 (95\% CI $1.78-2.85)$.

Exploratory analysis of CA subgroups. We observed more cases of spina bifida than expected in the lamotrigine-exposed group, but only for polytherapy (table 5). We found a significant excess of respiratory anomalies for lamotrigine monotherapy (table 5). These cases were heterogeneous in diagnosis (table 5). They include 5 cases of stenosis of the upper airways.

DISCUSSION This study of lamotrigine exposure in early pregnancy more than doubled the size of the previous study population ${ }^{13}$ (from 3.8 to 10 million births) and added a period from 2006 onward when lamotrigine exposure was nearly 3 times more prevalent. Our estimate of the risk of OC relative to other anomalies is nonsignificant with an upper confidence limit of 2.3 and therefore does not support the 6-fold risk suggested by the North American AED cohort results. ${ }^{10}$ Our results concur with other studies published since the original signal, ${ }^{4,6,11,12}$ which do not find a large excess of $\mathrm{OC}$ or cleft palate. One of the reasons for the discrepancy with the original signal may be that our baseline population risk of OC is 1.4 per 1,000 , rather than the 0.7 per 1,000 baseline estimated by the North American cohort, ${ }^{10}$ later revised upwards to 1.1 per $1,000.5$ The size of the original OC signal may also have been a chance finding, or exacerbated by coexposures. Based on our European OC prevalence rate of 1.4 per 1,000, and an upper confidence limit of OR of 2.3, we estimate exposure to lamotrigine would result in OC in less than 1 in every 550 exposed babies.

Cleft palate is considered to be etiologically distinct from cleft lip with or without palate,$^{20}$ although poor recording may lead to misclassification in some studies in the literature. In a previous EUROCAT study of $\mathrm{VPA},{ }^{21}$ we found an OR of 5.2 for cleft palate with no increased risk for cleft lip. A previous EUROCAT study of carbamazepine ${ }^{22}$ found no excess of cleft lip and a small nonsignificant OR of 1.3 for cleft palate, ${ }^{22}$ whereas an excess of cleft lip was reported in cohort studies in the literature..$^{22}$ There is a strong signal in the literature for topiramate and OC, particularly cleft lip. ${ }^{5}$ We find a small excess risk of OC with any AED excluding VPA of borderline statistical significance (OR 1.33). However, due to the case-malformed control design, this would be diluted by inclusion of malformations associated with AED in the control group (such as spina bifida associated with carbamazepine ${ }^{22}$ ). The similarity with the point estimate of OR for lamotrigine (1.31) is therefore difficult to interpret. OC have long been found to be associated with anticonvulsant exposures of many types, ${ }^{23}$ and there is inconclusive evidence addressing hypotheses as to whether some types of epilepsy may be genetically linked to $\mathrm{OC},{ }^{23}$ whether anticonvulsant medication accentuates the underlying genetic tendency, ${ }^{23}$ or whether the medication effects are independent of epilepsy. Given this context, it is prudent to examine the baby of any woman with epilepsy carefully for cleft palate, which may not be externally visible, regardless of her medication.

In our previous study, ${ }^{13}$ we found a significant excess of clubfoot. We have now validated the recording of clubfoot as a major CA by EUROCAT registries. The only other evidence to support this association has been 3 cases in 802 exposed 
Table 5 Distribution ${ }^{\mathrm{a}}$ of anomaly subgroups by lamotrigine exposure status

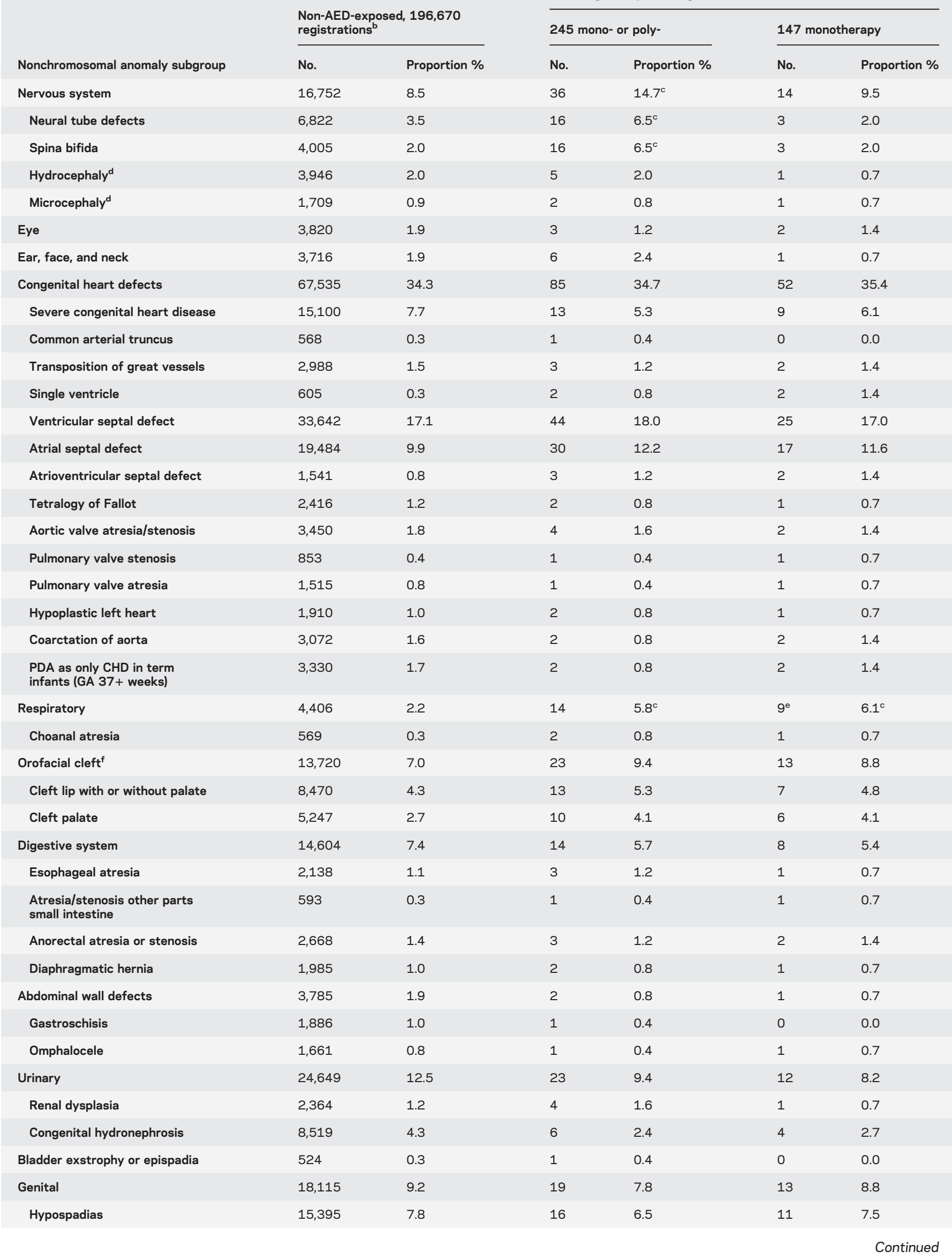


Table 5 Continued

\begin{tabular}{|c|c|c|c|c|c|c|}
\hline \multirow[b]{3}{*}{ Nonchromosomal anomaly subgroup } & \multirow{2}{*}{\multicolumn{2}{|c|}{$\begin{array}{l}\text { Non-AED-exposed, 196,670 } \\
\text { registrations }^{b}\end{array}$}} & \multicolumn{4}{|c|}{ Lamotrigine-exposed registrations } \\
\hline & & & \multicolumn{2}{|c|}{245 mono- or poly- } & \multicolumn{2}{|c|}{147 monotherapy } \\
\hline & No. & Proportion \% & No. & Proportion \% & No. & Proportion \% \\
\hline Limb & 39,652 & 20.2 & 62 & $25.3^{c}$ & 41 & $27.9^{c}$ \\
\hline Limb reduction & 5,162 & 2.6 & 6 & 2.4 & 2 & 1.4 \\
\hline Upper limb reduction & 3,724 & 1.9 & 4 & 1.6 & 2 & 1.4 \\
\hline Clubfoot $^{d}$ & 9,042 & 4.6 & 15 & 6.1 & 12 & $8.2^{c}$ \\
\hline Hip dislocation/dysplasia & 5,814 & 3.0 & 7 & 2.9 & 4 & 2.7 \\
\hline Polydactyly & 8,789 & 4.5 & 12 & 4.9 & 7 & 4.8 \\
\hline Syndactyly & 4,660 & 2.4 & 7 & 2.9 & 5 & 3.4 \\
\hline
\end{tabular}

Abbreviations: $\mathrm{AED}=$ antiepileptic drug; $\mathrm{CHD}=$ congenital heart defect; $\mathrm{GA}=$ gestational age; $\mathrm{PDA}=$ patent ductus arteriosus.

a One infant/fetus can be counted in more than one subgroup if he or she has multiple malformations, but only once in the total. Only subgroups with at least one lamotrigine-exposed registration are shown.

${ }^{b}$ A total of 197,948 nonchromosomal registrations (figure e-1) minus 1,278 nonchromosomal AED-exposed.

${ }^{c} p<0.05$ In exploratory analyses using Fisher exact test.

${ }^{\mathrm{d}}$ Excluding cases associated with spina bifida.

${ }^{\mathrm{e}}$ Including 1 case of atresia of larynx and 1 of laryngeal stenosis, 1 choanal atresia, 2 cases of congenital subglottic stenosis, 2 cases of pulmonary hypoplasia with other major malformations, 1 secondary pulmonary hypoplasia, and 1 isolated case of pulmonary hypoplasia, which is on the EUROCAT list of minor anomalies for exclusion when isolated but was miscoded.

${ }^{\mathrm{f}}$ Secondary clefts excluded (of which none of the patients were exposed to lamotrigine).

pregnancies reported by the International Lamotrigine Pregnancy Registry. ${ }^{4}$ We sought to confirm the signal ${ }^{13}$ in an independent dataset to exclude the possibility of it being a chance finding. We could not find statistically significant independent evidence of a clubfoot excess. However, the overall excess including the original signal remains statistically significant. We recommend that cohort studies also keep this anomaly under review using comparable diagnostic inclusion criteria. Clubfoot has been associated with exposure to various medications including selective serotonin reuptake inhibitors. ${ }^{24-26}$

No other CA were found to be associated with lamotrigine monotherapy. An excess of respiratory anomalies may be too heterogeneous to be interpreted as causally associated, and may be a chance finding due to the multiple comparisons performed, but due to differing interpretations among reviewers of these data we recommend other studies should follow-up stenosis of the upper airways.

Limitations of case-malformed control studies are that without a nonmalformed control group it is not possible to estimate the overall CA risk associated with exposure and that estimated OR may be diluted if controls include CA associated with exposure. Cohort studies have found an overall CA rate associated with lamotrigine exposure similar to background expectation $^{3-6}$ but do not have exact external comparators. We estimated the OR of nonchromosomal CA by comparing with chromosomal syndromes, assuming the latter to reflect population exposure. The OR, adjusted for maternal age, of 1.77 (95\% CI $0.93-3.37$ ), although not statistically significant and with a wide $\mathrm{CI}$, is consistent with a small generalized excess of nonchromosomal CA, and thus an underestimation of our ORs for OC and clubfoot. However, the elevated OR may also reflect some underascertainment of lamotrigine exposure among TOPFA, which are more common in chromosomal syndromes.

The strengths of our study are the large sample size, population base, detailed and standardized diagnostic data on CA, and inclusion of TOPFA, which constitute a large proportion of some $\mathrm{CA}^{27}$ Due to the rarity of $\mathrm{OC}$ and of lamotrigine exposure, the power to detect clinically significant associations remains limited and we therefore used the upper CI of the OR estimates for OC when estimating excess risk. Unlike most AED cohort studies, we have an internal comparator group. AED exposure was mainly prospectively ascertained, and the case-malformed control study design reduces recall and information bias. The AED exposure rate of 6.0 per 1,000 suggests good ascertainment, taking into account the expected population AED exposure rate of $3-5$ per $1,000^{1}$ and the excess risk of CA among the AED exposed. ${ }^{21,22}$ We did not 
have information on dose, which would have been of interest given conflicting results concerning a doseresponse effect for lamotrigine ${ }^{3-6,28}$ and therefore our results are relevant to average dose in the population.

\section{AUTHOR CONTRIBUTIONS}

Prof. H. Dolk: drafting/revising the manuscript for content, study concept or design, analysis of interpretation of data, acquisition of data, statistical analysis, study supervision or coordination, obtaining funding. Dr. H. Wang: drafting/revising the manuscript for content, analysis or interpretation of data, acquisition of data, statistical analysis. Dr. M. Loane: drafting/revising the manuscript for content, study concept or design, analysis of interpretation of data, statistical analysis, study supervision or coordination, obtaining funding, data management. Prof. J. Morris: drafting/ revising the manuscript for content, analysis or interpretation of data, statistical analysis. Dr. E. Garne: drafting/revising the manuscript for content, study concept or design, analysis of interpretation of data, acquisition of data, classification of cases. Dr. M.-C. Addor: drafting/revising the manuscript for content, acquisition of data. Dr. L. Arriola: drafting/revising the manuscript for content, acquisition of data. Dr. M. Bakker: drafting/ revising the manuscript for content, study concept or design, analysis or interpretation of data, acquisition of data. Prof. I. Barisic: drafting/revising the manuscript for content, analysis or interpretation of data, acquisition of data. Dr. M. Gatt: drafting/revising the manuscript for content, acquisition of data. Dr. B. Doray: analysis or interpretation of data, acquisition of data. Prof. K. Kallen: drafting/revising the manuscript for content, study concept or design, analysis or interpretation of data, acquisition of data, obtaining funding, funding for the Swedish programme, independent from Glaxo. Dr. B. Khoshnood: drafting/revising the manuscript for content, analysis or interpretation of data, acquisition of data, obtaining funding. Dr. K. Klungsoyr: drafting/revising the manuscript for content, acquisition of data. Dr. A.-M. Lahesmaa-Korpinen: drafting/revising the manuscript for content, analysis or interpretation of data, acquisition of data. Dr. A. LatosBielenska: analysis or interpretation of data, acquisition of data, obtaining funding. Dr. J.P. Mejnartowicz: drafting/revising the manuscript for content, acquisition of data. Dr. V. Nelen: drafting/revising the manuscript for content, acquisition of data. Dr. A. Neville: drafting/revising the manuscript for content, analysis or interpretation of data, acquisition of data. Dr. M. O'Mahony: drafting/revising the manuscript for content, analysis or interpretation of data, acquisition of data. Dr. A. Pierini: drafting/revising the manuscript for content, study concept or design, analysis or interpretation of data, acquisition of data. Dr. A. Rissmann: drafting/revising the manuscript for content, analysis or interpretation of data, acquisition of data. D. Tucker: drafting/revising the manuscript for content, analysis or interpretation of data, acquisition of data. Dr. D. Wellesley: drafting/ revising the manuscript for content, analysis or interpretation of data. Dr. A. Wiesel: drafting/revising the manuscript for content, analysis or interpretation of data, acquisition of data. Prof. L.T.W. de Jong-van den Berg: drafting/revising the manuscript for content, study concept or design, analysis of interpretation of data, study supervision or coordination, obtaining funding.

\section{ACKNOWLEDGMENT}

The authors thank the members of the External Advisory Committee (Dr. Jim Morrow, UK Epilepsy and Pregnancy Register; Dr. Christof Schaefer, Berlin Teratology Information Unit; Dr. David Prieto, London School of Hygiene and Tropical Medicine) for their comments each of 5 years on interim analysis reports; Prof. Christine Verellen-Dumoulin (Centre de Génétique Humaine Institut de Pathologie et de Génétique), Belgium, who contributed data to a previous paper on this subject, which were also included here; Prof. Elisa Calzolari, who contributed to the classification of cases for the study as member of the EUROCAT Coding \& Classification Committee and made comments on earlier drafts; and Dr. Annukka Ritvanen for her involvement in contributing Finnish data and comments on earlier drafts.

\section{STUDY FUNDING}

The EUROCAT Central Database was funded by the EU Public Health Programme. Additional funding for this study was a grant from GlaxoSmithKline. GSK approved the protocol for this study prior to contract, but has not been involved in the conduct or management of the study, or analysis or interpretation of data or preparation of the paper. There were no other conflicts of interest. The External Advisory Committee had no direct or indirect financial relationship with GSK. This study was sponsored by GlaxoSmithKline.

\section{DISCLOSURE}

H. Dolk's institution received funding from GlaxoSmithKline, via Ulster University, for data or staff time contributed to this study. H. Wang's institution received funding from GlaxoSmithKline, via Ulster University, for data or staff time contributed to this study. M. Loane's institution received funding from GlaxoSmithKline, via Ulster University, for data or staff time contributed to this study. J. Morris' institution received funding from GlaxoSmithKline, via Ulster University, for data or staff time contributed to this study. E. Garne's institution received funding from GlaxoSmithKline, via Ulster University, for data or staff time contributed to this study. M.-C. Addor's institution received funding from GlaxoSmithKline, via Ulster University, for data or staff time contributed to this study. L. Arriola's institution received funding from GlaxoSmithKline, via Ulster University, for data or staff time contributed to this study. M. Bakker's institution received funding from GlaxoSmithKline, via Ulster University, for data or staff time contributed to this study. I. Barisic's institution received funding from GlaxoSmithKline, via Ulster University, for data or staff time contributed to this study. B. Doray reports no disclosures relevant to the manuscript. M. Gatt's institution received funding from GlaxoSmithKline, via Ulster University, for data or staff time contributed to this study. K. Kallen reports no disclosures relevant to the manuscript. B. Khoshnood's institution received funding from GlaxoSmithKline, via Ulster University, for data or staff time contributed to this study. K. Klungsoyr reports no disclosures relevant to the manuscript. A-M. Lahesmaa-Korpinen's institution received funding from GlaxoSmithKline, via Ulster University, for data or staff time contributed to this study. A. Latos-Bielenska's institution received funding from GlaxoSmithKline, via Ulster University, for data or staff time contributed to this study. J. Mejnartowicz's institution received funding from GlaxoSmithKline, via Ulster University, for data or staff time contributed to this study. V. Nelen's institution received funding from GlaxoSmithKline, via Ulster University, for data or staff time contributed to this study. A. Neville's institution received funding from GlaxoSmithKline, via Ulster University, for data or staff time contributed to this study. M. O'Mahoney's institution received funding from GlaxoSmithKline, via Ulster University, for data or staff time contributed to this study. A. Pierini's institution received funding from GlaxoSmithKline, via Ulster University, for data or staff time contributed to this study. A. Rissmann's institution received funding from GlaxoSmithKline, via Ulster University, for data or staff time contributed to this study. D. Tucker's institution received funding from GlaxoSmithKline, via Ulster University, for data or staff time contributed to this study. David Tucker (Public Health Wales NHS Trust, UK) is a GSK shareholder since 2013. D. Wellesley reports no disclosures relevant to the manuscript. A. Wiesel's institution received funding from GlaxoSmithKline, via Ulster University, for data or staff time contributed to this study. L. de Jong-van den Berg's institution received funding from GlaxoSmithKline, via Ulster University, for data or staff time contributed to this study. Go to Neurology.org for full disclosures.

Received June 19, 2015. Accepted in final form January 26, 2016.

\section{REFERENCES}

1. Charlton RA, Garne E, Wang H, et al. Antiepileptic drug prescribing before, during and after pregnancy: a study in 7 European regions. Pharmacoepidemiol Drug Saf 2014; 23:22-23.

2. Medicines and Healthcare Products Regulatory Agency (MHRA) Patient Information Leaflet. Lamotrigine. Available at: http://www.mhra.gov.uk/home/groups/spcpil/documents/ spcpil/con1404109838676.pdf. Accessed March 22, 2016.

3. Campbell E, Kennedy F, Russell A, et al. Malformation risks of antiepileptic drug monotherapies in pregnancy: 
updated results from the UK and Ireland Epilepsy and Pregnancy Registers. J Neurol Neurosurg Psychiatry 2014;85:1029-1034.

4. Cunnington MC, Weil JG, Messenheimer JA, Ferber S, Yerby M, Tennis P. Final results from 18 years of the international lamotrigine pregnancy registry. Neurology 2011;76:1817-1823.

5. Hernandez-Diaz S, Smith CR, Shen A, et al. Comparative safety of antiepileptic drugs during pregnancy. Neurology 2012;78:1692-1699.

6. Tomson T, Battino D, Bonizzoni E, et al. Dose-dependent risk of malformations with antiepileptic drugs: an analysis of data from the EURAP epilepsy and pregnancy registry. Lancet Neurol 2011;10:609-617.

7. Tran TA, Leppik IE, Blesi K, Sathanandan ST, Remmel R. Lamotrigine clearance during pregnancy. Neurology 2002;59:251-255.

8. Marson AG, Appleton R, Baker GA, et al. A randomised controlled trial examining the longer-term outcomes of standard versus new antiepileptic drugs: the SANAD trial. Health Technol Assess 2007;11:iii-iv, ix-x, 1-134.

9. US Food and Drug Administration. FDA alert September 2006. Available at: http://www.fda.gov/Safety/MedWatch/ SafetyInformation/SafetyAlertsforHumanMedicalProducts/ ucm150637.htm. Accessed March 22, 2016.

10. Holmes LB, Baldwin EJ, Smith CR, et al. Increased frequency of isolated cleft palate in infants exposed to lamotrigine during pregnancy. Neurology 2008;70:2152-2158.

11. Hunt SJ, Craig JJ, Morrow JI. Increased frequency of isolated cleft palate in infants exposed to lamotrigine during pregnancy. Neurology 2009;72:1108.

12. Mølgaard-Nielsen D, Hviid A. Newer-generation antiepileptic drugs and the risk of major birth defects. JAMA 2011;305:1996-2002.

13. Dolk H, Jentink J, Loane MA, Morris JK, de Jong-van den Berg LT; EUROCAT Antiepileptic Drug Working Group. Does lamotrigine use in pregnancy increase orofacial cleft risk relative to other malformations? Neurology 2008;71:714-722.

14. Boyd P, Barisic I, Haeusler M, Loane M, Garne E, Dolk H. Paper 1: the EUROCAT network: organization and processes. Birth Defects Res A Clin Mol Teratol 2011;91:2-15.

15. EUROCAT. EUROCAT Guide 1.3 and Reference Documents, Instructions for the Registration and Surveillance of Congenital Anomalies, September 2005. Available at: http://www.eurocat.ulster.ac.uk/pdf/EUROCAT-Guide-1.3. pdf. Accessed April 3, 2015.

16. WHO Collaborating Centre for Drug Statistics Methodology. Anatomical Therapeutic Chemical Classification
System. Available at: http://www.whocc.no/atc_ddd_ index/. Accessed April 3, 2015.

17. EUROCAT. EUROCAT Special Report: Sources of Information of Medication Use in Pregnancy. EUROCAT Central Registry, University of Ulster; 2014. Available at: http://www.eurocat-network.eu/content/Special-ReportMedication-Use-In-Pregnancy.pdf. Accessed April 3, 2015.

18. Garne E, Dolk H, Loane M, et al. Paper 5: surveillance of multiple congenital anomalies: implementation of a computer algorithm in European registers for classification of cases. Birth Defects Res A Clin Mol Teratol 2011;91: S44-S50.

19. Loane M, Dolk H, Morris J; EUROCAT Working Group. Maternal age-specific risk of non-chromosomal anomalies. BJOG 2009;116:1111-1119.

20. FitzPatrick DR, Raine PAM, Boorman JG. Facial clefts in the west of Scotland in the period 1980-1984: epidemiology and genetic diagnoses. J Med Genet 1994;31: 126-129.

21. Jentink J, Loane MA, Dolk H, et al. Valproic acid monotherapy exposure in the first trimester of pregnancy and risk of specific birth defects. N Engl J Med 2010b;362: 2185-2193.

22. Jentink J, Dolk H, Loane M, Morris JK, de Jong-van den Berg L; for the EUROCAT Antiepileptic Drug Working Group. Carbamazepine monotherapy exposure in the first trimester of pregnancy and risk of specific birth defects. BMJ 2010;341:c6581.

23. Schardein JL. Chemically Induced Birth Defects. 3rd ed, New York: Marcel Dekker; 2000.

24. Yazdy MM, Michell AA, Louik C, Werler MM. Use of selective serotonin-reuptake inhibitors during pregnancy and the risk of clubfoot. Epidemiology 2014;25:859-865.

25. Wemakor A, Casson K, Garne E, et al. Selective serotonin reuptake inhibitor antidepressant use in first trimester pregnancy and risk of specific congenital anomalies: a European register-based study. Eur J Epidemiol 2015;30: 1187-1198.

26. Werler MM, Yazdy MM, Kasser JR, et al. Medication use in pregnancy in relation to the risk of isolated clubfoot in offspring. Am J Epidemiol 2014;180:86-93.

27. Garne E, Dolk H, Loane M, Boyd P; EUROCAT Working Group. EUROCAT website data on prenatal detection rates of congenital anomalies. J Med Screen 2010;17:97-98.

28. Vajda FJ, O’Brien TJ, Lander CM, Graham J, Eadie MJ. The teratogenicity of the newer antiepileptic drugs: an update. Acta Neurol Scand 2014;130:234-238. 


\section{Neurology}

\section{Lamotrigine use in pregnancy and risk of orofacial cleft and other congenital anomalies}

Helen Dolk, Hao Wang, Maria Loane, et al.

Neurology 2016;86;1716-1725 Published Online before print April 6, 2016

DOI 10.1212/WNL.0000000000002540

\section{This information is current as of April 6, 2016}

\section{Updated Information \& Services \\ Supplementary Material}

\section{References}

Subspecialty Collections

\section{Permissions \& Licensing}

Reprints including high resolution figures, can be found at: http://n.neurology.org/content/86/18/1716.full

Supplementary material can be found at: http://n.neurology.org/content/suppl/2016/04/05/WNL.0000000000002 540.DC1

This article cites 21 articles, 9 of which you can access for free at: http://n.neurology.org/content/86/18/1716.full\#ref-list-1

This article, along with others on similar topics, appears in the following collection(s):

Antiepileptic drugs

http://n.neurology.org/cgi/collection/antiepileptic_drugs Case control studies

http://n.neurology.org/cgi/collection/case_control_studies

Developmental disorders

http://n.neurology.org/cgi/collection/developmental_disorders

Harm/ risk (analysis)

http://n.neurology.org/cgi/collection/harm_risk_analysis

Information about reproducing this article in parts (figures,tables) or in its entirety can be found online at:

http://www.neurology.org/about/about_the_journal\#permissions

Information about ordering reprints can be found online: http://n.neurology.org/subscribers/advertise

Neurology ${ }^{\circledR}$ is the official journal of the American Academy of Neurology. Published continuously since 1951, it is now a weekly with 48 issues per year. Copyright @ 2016 American Academy of Neurology. All rights reserved. Print ISSN: 0028-3878. Online ISSN: 1526-632X.

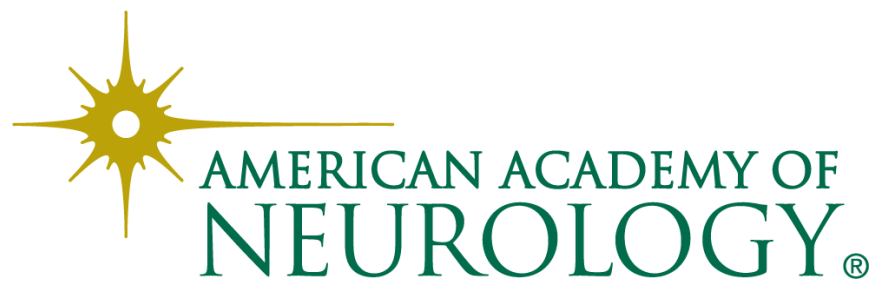

